\title{
Investigations on Vinylene Carbonate. IV. Radiation Induced Graft Copolymerization of Vinylene Carbonate and $\mathrm{N}$-Vinyl-N-Methylacetamide onto Polyethylene Films
}

\author{
GUOHUA CHEN, LEEN VAN DER DOES, and ADRIAAN BANTJES \\ Department of Chemical Technology, Biomaterials Section, Twente University, \\ P.O. Box 217, 7500 AE Enschede, The Netherlands
}

\begin{abstract}
SYNOPSIS
Graft copolymerization of binary mixtures of vinylene carbonate (VCA) and N-vinyl-Nmethylacetamide (VIMA) onto low density polyethylene (LDPE) films was studied by the mutual $\gamma$-irradiation technique. Sufficient amounts of functionally active VCA groups could be grafted onto the surface and the hydrophilicity of the surface was also improved. The grafting of VCA onto polyethylene films in the binary solutions was found to be promoted by the presence of VIMA, thus showing a positive synergism. The VCA content in the graft copolymers was always higher than in the copolymers obtained by homogeneous copolymerization using the same monomer feed composition. The monomer reactivity ratios, as well as a preferential partitioning of the monomers surrounding the polymeric substrate, were considered to explain the grafting reactions in the binary systems.
\end{abstract}

\section{INTRODUCTION}

Surface modification of polymers has received a great deal of attention during the last decades since it could bring about specific surface properties including adhesion, printability, nonthrombogenicity, and antistatic properties, among others.

Since the major problems for application of biomaterials that contact blood occur at the blood-material interface, much research has focused in recent years on the creation of biocompatible surfaces. Grafting of monomers makes it possible to introduce a wide variety of properties on the surface.

As suggested by Andrade et al., ${ }^{1}$ hydrogels are highly blood compatible because of their low interfacial energy when in contact with blood. Hydrogels and hydrophilic surfaces have been developed by graft polymerization of hydrophilic monomers, such as 2-hydroxyethyl methacrylate (HEMA), $\mathrm{N}$-vinylpyrrolidone (NVP), or acrylamide (AAm), ${ }^{2-6}$ onto hydrophobic polymers. The grafted substrates showed an improved blood compatibility as compared with the nongrafted polymeric supports.

Journal of Applied Polymer Science, Vol. 45, 853-864 (1992)
It has been proved that the biological endothelium owes its nonthrombogenic character to its negative charge so that it is obvious that the chemical group distribution involving polar and nonpolar components plays a significant role in blood compatibility. ${ }^{7}$ In addition, a particular ratio of hydrophilic to hydrophobic sites on a surface may be important for optimal blood compatibility. ${ }^{8,9}$ Attempts have been made to elucidate the interrelationship between the hydrophilic-hydrophobic composition of a polymeric material and the biological interactions with that material by graft copolymerization of mixtures of hydrophilic monomers, such as HEMA, and hydrophobic monomers, such as ethyl methacrylate (EMA), onto a polymeric matrix..$^{10,11}$

On the other hand, as combinations of polymeric materials with physiologically active substances, such as heparin ${ }^{12}$ and prostaglandin, ${ }^{13}$ which inhibit fibrin deposition, or fibrinolytic enzymes, such as urokinase ${ }^{14}$ have exhibited a good blood compatibility, some efforts have been made to functionalize the polymeric surface with reactive groups for further immobilization of bioactive agents. Glycidyl methacrylate (GMA), ${ }^{15}$ containing a functionally reactive epoxy group, or acrylic acid (AA), ${ }^{16,17}$ has been grafted onto polymeric supports and was used 
for immobilization of bioactive compounds in order to get blood compatible materials.

The cyclic carbonate groups in polymers of vinylene carbonate (VCA), a disubstituted unsaturated cyclic ethylene derivative, have been used for coupling enzymes, antigens, etc., by reaction with amino groups. ${ }^{18-20}$ Even though such important qualities are manifested by VCA, its grafting on a suitable polymeric matrix has scarcely been studied. $^{21,22}$ Since polymers with VCA groups could react with amino groups under very mild conditions without activation, it might be of interest to graft VCA onto polymeric surfaces for immobilization of bioactive agents in order to get good blood compatible materials.

Therefore in our study, attempts have been made to modify low density polyethylene (LDPE) films in order to get polymers with hydrophilic surfaces and with sufficient amounts of VCA groups. Graft polymerization of VCA was studied as well as grafting of mixtures of VCA and N-vinyl-N-methylacetamide (VIMA). The behavior of this pair of monomers in the graft copolymerization was of interest because we recently reported the homogeneous copolymerization of VCA with VIMA in acetone. ${ }^{23}$ VIMA was also chosen because it has been grafted onto some polymeric substrates to provide hydrophilic surfaces with a good blood compatibility. ${ }^{21,24}$ In this article, grafting conditions, as well as the effects of monomer feed composition, monomer concentration, solvents, and radiation dose on the grafting reaction, will be discussed. Because grafting of mixtures of VCA and VIMA onto LDPE films in methanol was studied in more detail, for comparison, the homogeneous copolymerization of VCA and VIMA in methanol was also investigated.

\section{EXPERIMENTAL}

\section{Materials}

$\mathrm{N}$-vinyl-N-methylacetamide (VIMA, Janssen Chimica, Beerse, Belgium) was distilled under reduced pressure before use; vinylene carbonate (VCA) was prepared as described in Ref. 25. All other chemicals were of analytical grade. Low density polyethylene (LDPE) sheets (Talas, Ommen, The Netherlands) with a thickness of $0.05 \mathrm{~mm}$, were cut into $10 \mathrm{~cm} \times 7.5 \mathrm{~cm}$ films $(\mathrm{ca} .0 .4 \mathrm{~g})$, cleaned for $15 \mathrm{~min}$ in a $1 \%(\mathrm{w} / \mathrm{v})$ detergent solution (Teepol, J. T. Baker Chemicals B. V., Deventer, The Netherlands), followed by extensive rinsing with distilled water and extraction with ethanol for $24 \mathrm{~h}$.

\section{Graft Copolymerization}

Polyethylene films were grafted by the mutual (or simultaneous) irradiation method, in which irradiation of the polymeric substrate is performed in the presence of monomer. Formation of polymer radicals for the initiation of the graft polymerization and the propagation takes place simultaneously. ${ }^{10,11}$

Graft polymerizations of vinylene carbonate (VCA), N-vinyl-N-methylacetamide (VIMA) and their mixtures onto low density polyethylene (LDPE) films were carried out by immersing the polyethylene films in the monomer solutions $(10 \mathrm{~mL}$ solvent with appropriate amounts of monomers) under nitrogen. Irradiation was performed with a ${ }^{60} \mathrm{Co}$ radiation source using a dose rate of $0.4 \mathrm{Mrad} /$ $\mathrm{h}$ at ambient temperature (Gammaster, Ede, The Netherlands). After irradiation, the films were extracted with methanol for 3 days ( soxhlet) to remove nongrafted copolymers or homopolymers formed during the grafting. Films grafted with a high VCA content in the solution $\left(f_{1}>0.6\right)$ or with VCA only were washed with DMF for 3 days to remove nongrafted copolymers or homopolymers. The films were then dried in a vacuum oven at $40^{\circ} \mathrm{C}$ for $24 \mathrm{~h}$. The grafting yield was calculated as

Grafting yield \% (w/w)

$$
=\left(\mathrm{W}_{\mathrm{d}}-\mathrm{W}_{0}\right) / \mathrm{W}_{0} \times 100 \%
$$

where $W_{d}=$ dry weight of the grafted polyethylene film $(\mathrm{g})$, and $\mathrm{W}_{0}=$ initial weight of the nongrafted polyethylene film $(\mathrm{g})$.

\section{Homogeneous Copolymerization}

Solution polymerization of VCA with VIMA in methanol ([VCA] + [VIMA] $=2.0 \mathrm{~mol} / \mathrm{L}(0.1 \mathrm{~mol}$ in $50 \mathrm{~mL}$ methanol)) was performed at $50^{\circ} \mathrm{C}$ in the presence of $0.6 \mathrm{~mol} \%$ of $2,2^{\prime}$-azoisobutyronitrile (AIBN), according to the procedure described in previous articles. ${ }^{23,26}$ The copolymers were precipitated in an excess of diethyl ether, washed with diethyl ether to remove monomers, and dried in a vacuum oven at $40^{\circ} \mathrm{C}$ for one night. Overall conversions were kept low (less than $5 \% \mathrm{w} / \mathrm{w}$ ).

\section{FT-IR Measurements and Composition Analysis}

IR measurements of the grafted polyethylene films, as well as of copolymers of VCA and VIMA, were carried out using a Bio-Rad FTS-60 FT-IR spectrophotometer. The operating parameters were: resolution $2 \mathrm{~cm}^{-1}$, scanning number 64 , absorbance 
measurements. The VCA content in the grafted polyethylene films was analyzed by FT-IR using a nongrafted polyethylene film as a background and a calibration curve of the corresponding VCA-VIMA copolymers with known compositions. ${ }^{23}$ The VCA content in the copolymers obtained by homogeneous copolymerization was also determined by FT-IR ( $\mathrm{KBr}$ discs) using the same calibration curve.

\section{Measurement of the Water Uptake of the Grafted Films}

The grafted films were placed in deionized water over a $24 \mathrm{~h}$ period with stirring. The samples were then weighed wet after blotting to remove the surface water. The water uptake of the grafted polyethylene films was calculated as follows:

Water uptake $\%(\mathrm{w} / \mathrm{w})$

$$
=\left(\mathrm{W}_{\mathrm{w}}-\mathrm{W}_{\mathrm{d}}\right) / \mathrm{W}_{\mathrm{d}} \times 100 \%
$$

where $\mathbf{W}_{\mathrm{w}}=$ wet weight of the blotted, grafted polyethylene film $(\mathrm{g})$, and $\mathrm{W}_{\mathrm{d}}=$ dry weight of the grafted polyethylene film $(\mathrm{g})$.

\section{Contact Angle Measurements}

The surfaces of the grafted films were also characterized by contact angle measurements (receding) using the captive bubble method. ${ }^{27}$ The films were

Table I Graft Polymerization of VCA onto Polyethylene Films by the Mutual $\gamma$-Irradiation Technique (Dose Rate, $0.4 \mathrm{Mrad} / \mathrm{h})^{\mathrm{a}}$

\begin{tabular}{lcrcc}
\hline \multicolumn{1}{c}{ Solvent } & $\begin{array}{c}\text { G }[\mathrm{M}] \\
(\mathrm{Mol} / \mathrm{L})\end{array}$ & $\begin{array}{c}\text { Dose } \\
(\mathrm{Mrad})\end{array}$ & $\begin{array}{c}\text { Yield } \\
(\% \mathrm{w} / \mathrm{w})\end{array}$ & $\begin{array}{c}\text { Contact } \\
\text { Angle } \\
\left({ }^{\circ}\right)\end{array}$ \\
\hline Acetone & 2.0 & 2.5 & 0.4 & $84 \pm 3$ \\
Acetone & 2.0 & 5.0 & 0.4 & \\
Acetone & 2.0 & 10.0 & 0.9 & \\
Dimethylform- & & & & \\
$\quad$ amide & 2.0 & 10.0 & 0.4 & $86 \pm 3$ \\
Dimethylform- & & & & \\
$\quad$ amide & 3.0 & 10.0 & 0.6 & \\
Methanol & 2.0 & 2.5 & 0.3 & $85 \pm 3$ \\
Methanol & 3.0 & 2.5 & 0.4 & \\
Ethanol & 2.0 & 2.5 & 0.2 & \\
$i$-Propanol & 2.0 & 2.5 & 0.6 & $85 \pm 3$ \\
$t$-Butanol & 2.0 & 2.5 & 3.5 & $81 \pm 3$ \\
\hline
\end{tabular}

The conversion including formation of homopolymer was in all cases less than $10 \%(\mathrm{w} / \mathrm{w})$; the contact angle of the nongrafted polyethylene films was $89^{\circ} \pm 2$.
Table II Graft Polymerization of VIMA onto Polyethylene Films by the Mutual $\gamma$-Irradiation Technique ${ }^{a}$

\begin{tabular}{lcccc}
\hline \multicolumn{1}{c}{ Solvent } & $\begin{array}{c}\text { Grafting } \\
\text { Yield } \\
(\mathrm{Mol} / \mathrm{L})\end{array}$ & $\begin{array}{c}\text { Water } \\
(\% \mathrm{w} / \mathrm{w})\end{array}$ & $\begin{array}{c}\text { Contake } \\
(\% \mathrm{w} / \mathrm{w})\end{array}$ & $\begin{array}{c}\text { Angle } \\
\left({ }^{\circ}\right)\end{array}$ \\
\hline Methanol & 0.5 & 3.2 & 1.2 & $67 \pm 3$ \\
Methanol & 1.0 & 10.1 & 4.1 & $46 \pm 2$ \\
Methanol & 2.0 & 20.3 & 11.5 & $27 \pm 2$ \\
Methanol & 3.0 & 29.7 & 14.8 & $26 \pm 2$ \\
Methanol & 4.0 & 37.5 & 22.2 & $26 \pm 2$ \\
Ethanol & 2.0 & 13.7 & 10.6 & $35 \pm 2$ \\
$i$-Propanol & 2.0 & 11.2 & 9.3 & $32 \pm 2$ \\
$t$-Butanol & 2.0 & 79.5 & 48.0 & $25 \pm 2$ \\
\hline
\end{tabular}

a The conversion including formation of homopolymer was in all cases less than $10 \%(\mathrm{w} / \mathrm{w})$; dose rate, $0.4 \mathrm{Mrad} / \mathrm{h}$; total radiation dose, 2.5 Mrad; the contact angle of the nongrafted polyethylene films was $89^{\circ} \pm 2$.

cut into small pieces (at least 6), fixed on a plastic matrix and immersed into doubly distilled water for $24 \mathrm{~h}$ before the measurements.

\section{RESULTS AND DISCUSSION}

\section{Individual Graft Polymerization of VCA and VIMA}

In order to find suitable solvents for VCA and VIMA to get homogeneous solutions for the grafting reactions, and to determine the optimum conditions for the cografting reactions, graft polymerization of the individual monomers onto LDPE films was studied in several solvents in which the LDPE films did not swell (Tables I and II). PolyVIMA is soluble in all the solvents mentioned, however, polyVCA is only soluble in DMF and acetone. It can be seen from Table I that in all the solvents except $t$-butanol, the amounts of VCA grafted on the polyethylene films were very low, which was also found by Fischer et al., who reported the graft polymerization of VCA onto polypropylene and LDPE films. ${ }^{21}$

However, the data in Table II show that VIMA could easily be grafted onto the LDPE films as has also been found by other researchers using $\gamma$ irradiation $^{21}$ or plasma treatment. ${ }^{24,28}$ Due to the VIMA grafting, a hydrophilic surface on the polyethylene films was formed, indicated by the water uptake and the decreased contact angles. The grafting yield depended on the monomer concentration and on the solvent, decreasing in the order $t$-butanol $\gg$ methanol $>$ ethanol $>i$-propanol. This result may 
be explained by the difference in the hydrogen abstraction rate of the alcohols (i.e., chain transfer rate to the solvent). In the graft polymerization system, when using, for example, $\mathrm{CH}_{3} \mathrm{OH}$ as a solvent, the following reactions may occur ${ }^{29}$ :

$\mathrm{PE}^{*}$ or $\mathrm{PE}-\mathrm{M}_{\mathrm{n}-1}^{*}+\mathrm{M} \rightarrow \mathrm{PE}-\mathrm{M}^{\bullet}$ or $\mathrm{PE}-\mathrm{M}_{\mathrm{n}}^{*}$

$\mathrm{PE}^{*}$ or $\mathrm{PE}-\mathrm{M}_{\mathrm{n}-1}^{\cdot}+\mathrm{CH}_{3} \mathrm{OH} \rightarrow$

PE-H or PE- $\mathrm{M}_{n-1}-\mathrm{H}+{ }^{\circ} \mathrm{CH}_{2} \mathrm{OH}$ where $\mathrm{PE}^{*}$ or $\mathrm{PE}-\mathrm{M}_{\mathrm{n}-1}^{\cdot}$ represent the macroradical or growing radical formed on the polyethylene film under the conditions of the experiment, and $\mathrm{M}$ denotes the monomer VIMA. When reaction (1) is operative, one will obtain the desired graft copolymer, whereas in the case of reaction (2), the radicals abstract an $\alpha \mathrm{H}$ atom from the alcohol leading to a decrease of the formation of graft polymer. From the knowledge of the rate constants for the reactions of $\mathrm{H}$ atoms with various alcohols, ${ }^{30,31}$ it was observed that the hydrogen abstraction rate constants from

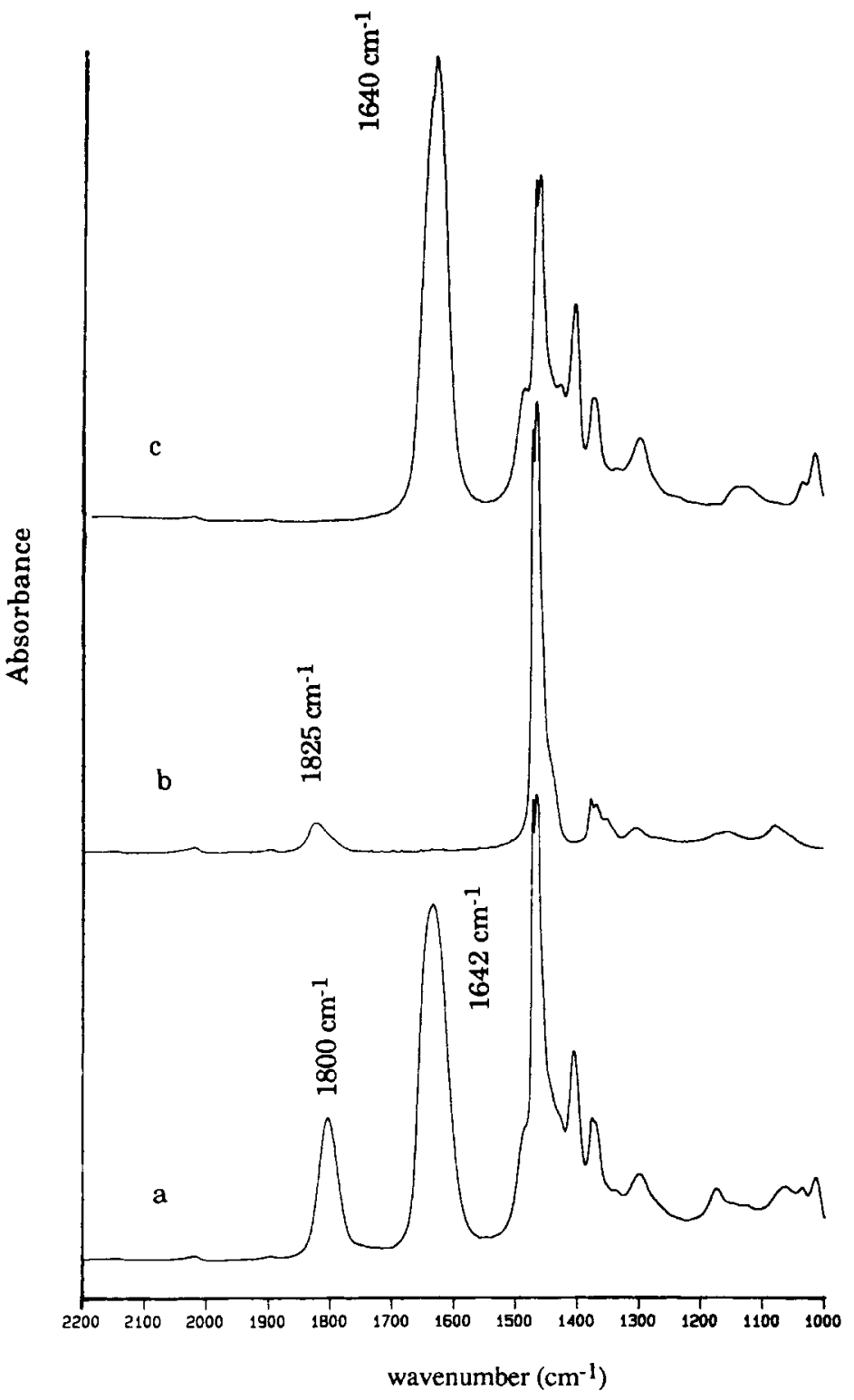

Figure 1 FT-IR spectra of grafted LDPE films. (a) grafted with a mixture of VCA and VIMA (molar ratio 40/60), (b) grafted with VCA, (c) grafted with VIMA. Grafting conditions: solvent, methanol; total monomer concentration, $2.0 \mathrm{~mol} / \mathrm{L}$; radiation dose, 2.5 Mrad; dose rate, $0.4 \mathrm{Mrad} / \mathrm{h}$. 
the respective alcohols decreased in the order $i$-propanol $>$ ethanol $>$ methanol $>t$-butanol. The result of this order is that reactions of type (2) (i.e., chain transfer to the solvent) will be most efficient when $i$-propanol is the solvent. ${ }^{31}$

On the other hand, grafting should be favored by using $t$-butanol as a solvent and the data from Table II show that an extremely high grafting yield was observed with $t$-butanol as compared with the other alcohols. This result might be caused by the low hydrogen abstraction rate as well as by the low polarity of the solvent, which would be favorable for VIMA to diffuse and to penetrate into the apolar polymeric substrate. Thus, a high local concentration of the monomer around the active sites in the polyethylene was created, resulting in a high grafting yield. (This could also explain the relatively higher grafting yield of VCA in $t$-butanol compared to that in the other alcohols (Table I)).

However, it should be noted that the VIMA grafted LDPE films in $t$-butanol showed a hydrogellike behavior, that is, the films swelled a lot in water with an accompanying loss of mechanical properties, indicating penetration of VIMA into the films, and grafting occurring not only on the surface, but also inside the films. Hence, $t$-butanol was not a suitable solvent for the surface modification.

Grafting of LDPE films with VIMA in the other alcohols, mentioned in Table II, resulted in grafted films that did not swell in water, but only adsorbed some water on the surface. Therefore, based on the preliminary results just mentioned, methanol was chosen as a solvent to study the graft copolymerization of mixtures of VCA and VIMA onto LDPE films.

\section{Graft Copolymerization of Mixtures of VCA and VIMA}

As discussed above, the grafting of VCA onto low density polyethylene (LDPE) films only yielded very small amounts of VCA groups on the films, whereas the surfaces of the films remained hydrophobic. Therefore, in order to create hydrophilic surfaces and to increase the grafting of functionally active VCA groups for immobilization of biological compounds, graft copolymerization of VCA with VIMA was attempted.

Figure 1 shows the FT-IR spectrum of a LDPE film grafted with a mixture of VCA and VIMA, and for comparison the spectra of LDPE films grafted with VCA and VIMA, respectively. The absorbances at $1800-1825 \mathrm{~cm}^{-1}$ can be assigned to the carbonate groups from the VCA units (Figs. 1a and $1 \mathrm{~b}$ ), and the absorbances at $c a .1640 \mathrm{~cm}^{-1}$ are referred to the carbonyl group from the VIMA units (Figs. 1a and 1c). It can be seen that the absorbance of the carbonate group is located at $1825 \mathrm{~cm}^{-1}$ for the VCA graft (Fig. 1b), which has also been observed for the homopolymer of VCA. ${ }^{23}$ However, using a mixture of VCA and VIMA for the grafting, the absorbance of the carbonate group shifted to a lower wavenumber (at $1800 \mathrm{~cm}^{-1}$, see Fig. 1a), which has also been observed in copolymers of VCA and VIMA obtained by homogeneous copolymerization, as reported in a previous article. ${ }^{23}$ Therefore, this result indicates that copolymers of VCA and VIMA instead of homopolymers were introduced on the films by the graft copolymerization.

The effect of the radiation time on the grafting yield and the VCA content in the graft copolymers is illustrated in Figure 2. It was found that with a constant dose rate and with the same total monomer concentration, the total grafting yield increases with the radiation time with a tendency to level off at longer radiation times as reported in the literature for other radiation graft copolymerization systems. ${ }^{11,32}$ The VCA content in the graft copolymers remained almost unaltered, whereas contact angles of $41-56^{\circ}$ were found, decreasing with increasing radiation time.

Figure 3 shows the effect of the total monomer concentration of VCA and VIMA in methanol on the grafting yields and the VCA content in the grafts on the LDPE films, in which the monomer molar ratios of VCA to VIMA used for the grafting were $0 / 100,20 / 80,40 / 60$, and $50 / 50$, respectively. As one would expect, the higher the monomer concen-

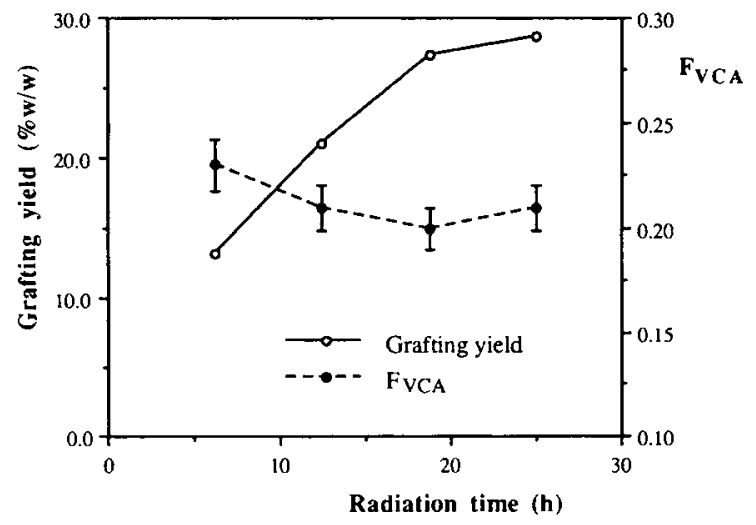

Figure 2 Effect of radiation time on grafting yield and VCA content of VCA-VIMA grafted LDPE films. Grafting conditions: solvent, methanol; total monomer concentration, $2.0 \mathrm{~mol} / \mathrm{L}$; molar monomer ratio of VCA to VIMA, 40/60; dose rate, $0.4 \mathrm{Mrad} / \mathrm{h}$. 

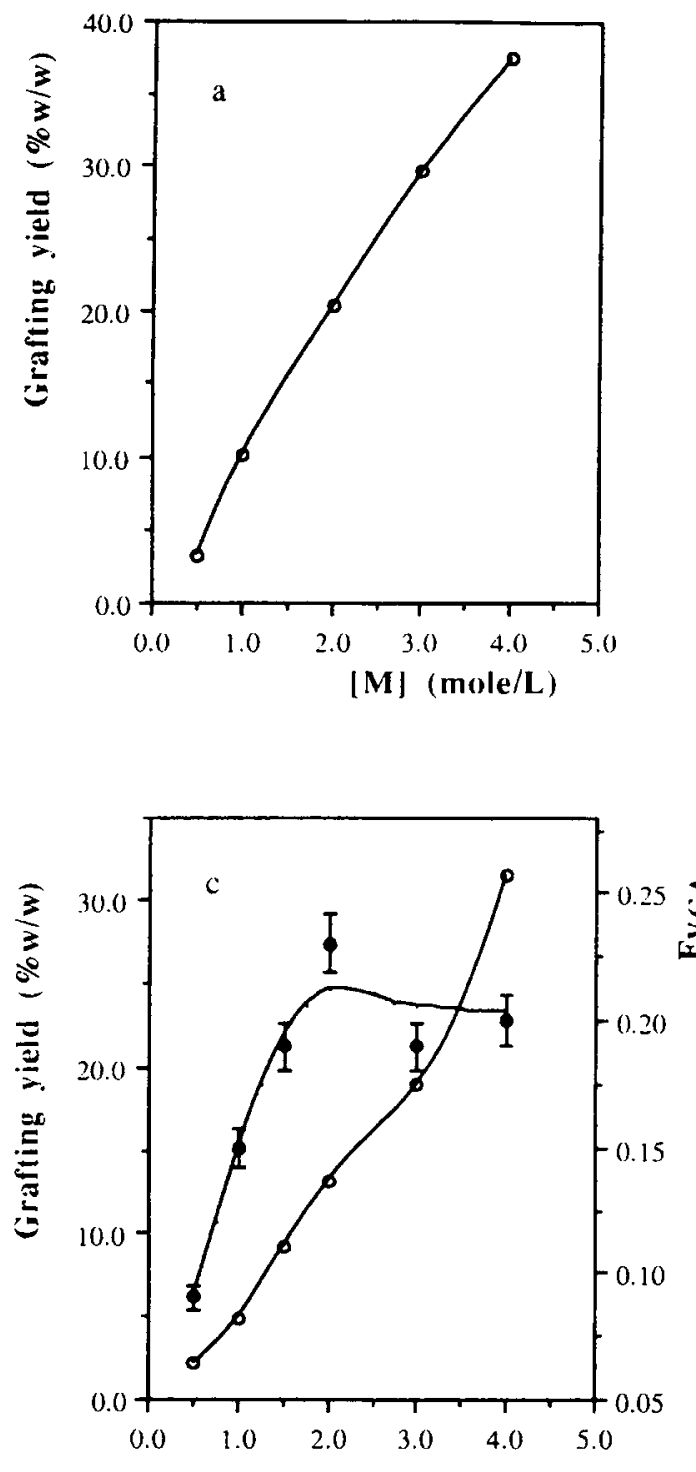

[M] (mole/L)
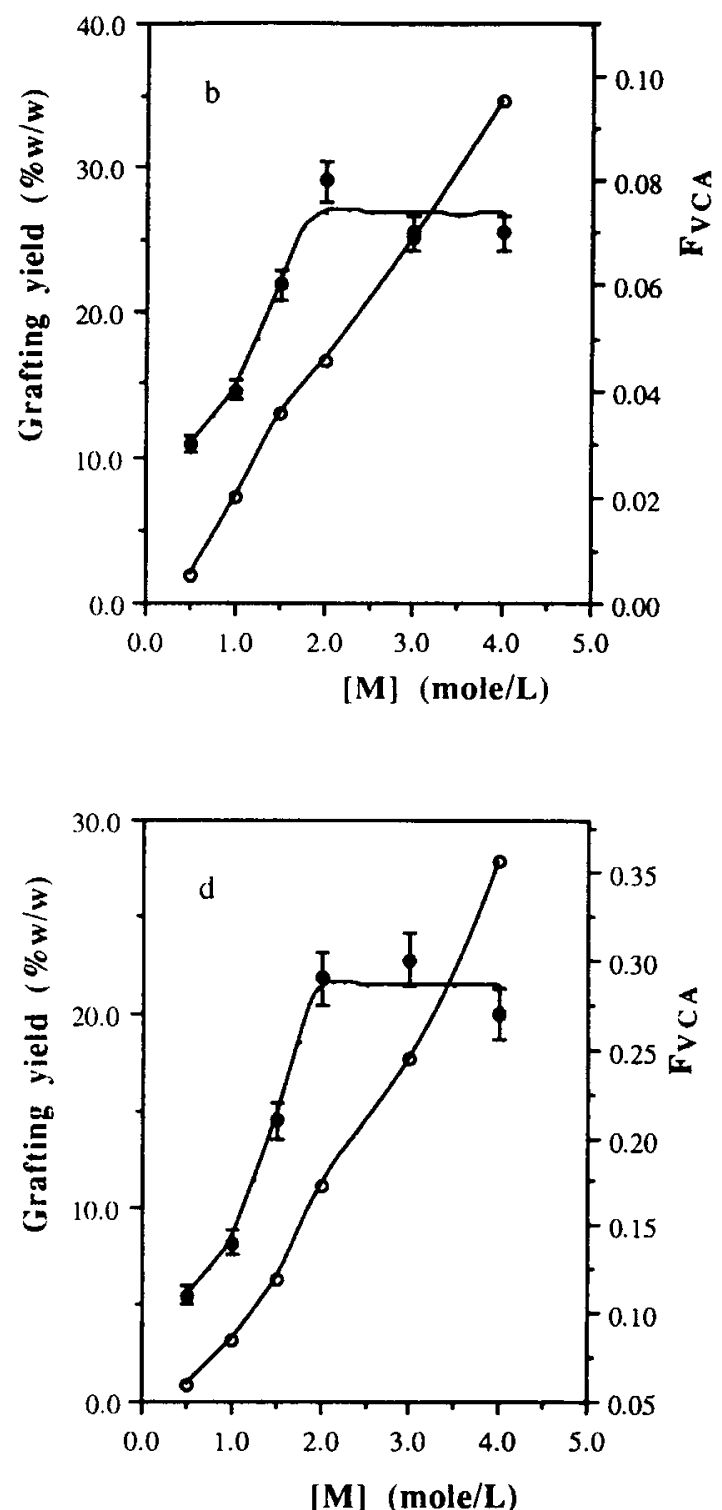

Figure 3 Effect of total monomer concentration on grafting yield and VCA content of VCA-VIMA grafted LDPE films (O) Grafting yield, (๑) $\mathbf{F}_{\mathrm{VCA}}$. Grafting conditions: solvent, methanol; radiation dose, $2.5 \mathrm{Mrad}$; dose rate, $0.4 \mathrm{Mrad} / \mathrm{h}$; molar monomer ratios of VCA to VIMA: (a) $0 / 100$, (b) $20 / 80$, (c) $40 / 60$, (d) $50 / 50$.

tration, the higher the grafting yield, for any monomer ratio. The VCA content in the graft copolymers was found to increase with the total monomer concentration to a certain value and then to level off or to decrease slightly (when $[\mathrm{M}] \geq 2.0 \mathrm{~mol} / \mathrm{L}$ ) for all the monomer ratios investigated. Therefore, in order to obtain a maximal grafting of VCA onto the polyethylene films, the total monomer concentration used in most experiments was chosen as $2.0 \mathrm{~mol} / \mathrm{L}$. Although the graft copolymerization of monomer mixtures on LDPE films (Figs. 3b-d) exhibits a similar dependence of the grafting yield on the total monomer concentration as the graft polymerization of VIMA (Fig. 3a), an increase of the VCA content in the solution reduces the grafting yield (see also Fig. 4).

Table III summarizes the results of the graft copolymerizations with several mixtures of VCA and VIMA onto LDPE films with the same total monomer concentration $(2.0 \mathrm{~mol} / \mathrm{L})$, but with different molar fractions of VCA in the solution. It was found that with the same total monomer concentration 


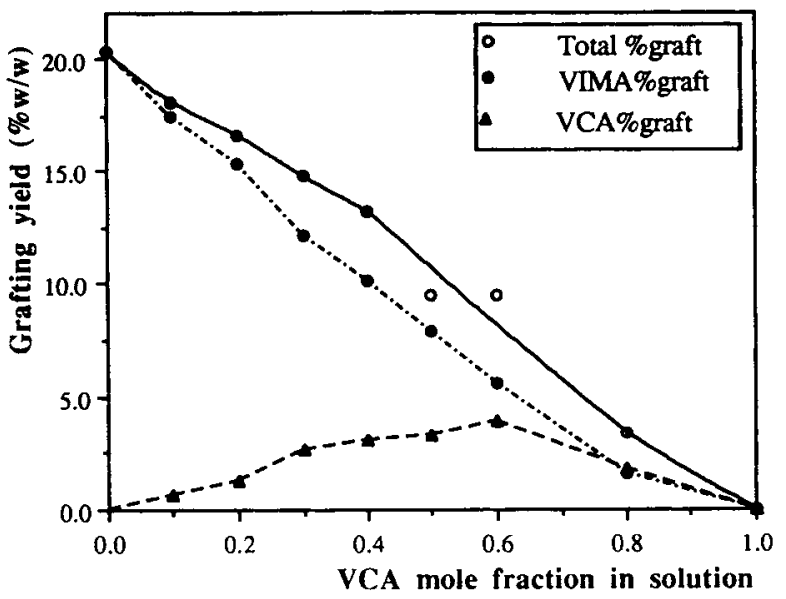

Figure 4 Effect of the VCA content on the graft copolymerization of VCA and VIMA onto polyethylene films. Grafting conditions: solvent, methanol; total monomer concentration, $2.0 \mathrm{~mol} / \mathrm{L}$; radiation dose, $2.5 \mathrm{Mrad}$; dose rate, $0.4 \mathrm{Mrad} / \mathrm{h}$.

( $2.0 \mathrm{~mol} / \mathrm{L}$ ), the grafting yield on the LDPE films decreased almost linearly with the increase of the VCA content in the solution (as seen in Fig. 4). The VCA content in the graft copolymers increased with the VCA content in the solution, whereas the hydrophilicity of the grafted films decreased. The higher the VCA content in the solution, the lower the water uptake and the higher the contact angle of the grafted LDPE films, due to the lower grafting yield and the higher VCA content in the grafted copolymers.

Figure 4 shows that the grafting yield of VIMA from the binary mixtures decreased with increasing VCA content in the mixtures, thus following the same trend as the total grafting yield. The grafting yield of VCA from the binary mixtures, however, increases with increasing VCA : VIMA molar ratios up to a VCA molar fraction in the solutions of 0.50.6 , for which the maximum grafting yield was obtained, and then decreased. Comparison with the individual graft polymerization of VCA onto polyethylene films under identical experimental conditions $\left(f_{\mathrm{vCA}}=1.0\right.$ in Fig. 4$)$ indicates that in the binary systems, much more grafting of VCA had occurred for all monomer ratios used, but with lower VCA concentrations (in the range of 0.2 to $1.6 \mathrm{~mol}$ / $\mathrm{L}$, dependent on the monomer ratios). It seems that the presence of VIMA enhances the grafting yield of VCA showing a positive synergism, as was found in other binary graft copolymerization systems with different monomers. ${ }^{33-35}$

From the results, shown in Table III and Figure 4 , we can draw the conclusion that the grafting yield of VCA on LDPE films could be increased to a sufficient amount, and, compared to the nongrafted film, relatively hydrophilic surfaces with functionally active groups could be obtained for immobilization of biologically active compounds.

Apart from the aim to increase the grafting of VCA on LDPE films by graft copolymerization with VIMA, we were also interested in the relationship between the VCA content in the monomer solutions and in the graft copolymers.

In a previous study, ${ }^{23}$ we investigated the homogeneous copolymerization of VCA and VIMA in acetone at $50^{\circ} \mathrm{C}$ and found for the monomer reactivity ratios: $r_{1(\mathrm{VCA})}=0.042$ and $r_{2(\mathrm{VIMA})}=4.16$, respectively. The monomer reactivity ratios of VCA and VIMA in the graft copolymerization on LDPE films in methanol were estimated ${ }^{36-39}$ by the graphical method according to the Kelen-Tudos (KT) ${ }^{40}$ equation, using the results given in Table III.

$$
\eta=\left(r_{1}+r_{2} / \alpha\right) \xi-r_{2} / \alpha(\mathrm{KT})
$$

A plot of $\eta$ vs. $\xi$, based on the Kelen-Tudos eq. (3), is shown in Figure 5, from which the monomer reactivity ratios were calculated:

$$
r_{1(\mathrm{VCA})}=0.38 \pm 0.04, \quad r_{2(\mathrm{VIMA})}=2.39 \pm 0.28
$$

In view of the disparity of the monomer reactivity ratios between graft copolymerization and homogeneous copolymerization, it was considered nec-

Table III Effect of Monomer Composition on Grafting Yield and Properties of VCA-VIMA Grafted Polyethylene Films ${ }^{\text {a }}$

\begin{tabular}{lcccc}
\hline & $\begin{array}{c}\text { Grafting } \\
\text { Yield } \\
(\% \text { w } / \text { w })\end{array}$ & $\begin{array}{c}\text { Water } \\
\text { Uptake } \\
(\% \text { w } / w)\end{array}$ & $\begin{array}{c}\text { Contact } \\
\text { Angle } \\
\left({ }^{\circ}\right)\end{array}$ & FCA $_{\text {vCA }}$ \\
\hline 0.00 & 20.3 & 11.5 & $27 \pm 2$ & - \\
0.10 & 18.1 & 7.0 & $33 \pm 2$ & 0.04 \\
0.20 & 16.6 & 5.6 & $40 \pm 2$ & 0.08 \\
0.30 & 14.8 & 4.4 & $42 \pm 3$ & 0.18 \\
0.40 & 13.2 & 3.1 & $56 \pm 3$ & 0.23 \\
0.50 & 11.2 & 2.3 & $69 \pm 2$ & 0.29 \\
0.60 & 9.5 & 1.7 & $75 \pm 2$ & 0.41 \\
0.80 & 3.4 & 0.4 & $84 \pm 3$ & 0.54 \\
1.00 & 0.3 & - & $85 \pm 3$ & - \\
\hline
\end{tabular}

${ }^{a}$ Grafting conditions: total monomer concentration, $2.0 \mathrm{~mol} /$ $\mathrm{L}$; dose rate, $0.4 \mathrm{Mrad} / \mathrm{h}$; total radiation dose, $2.5 \mathrm{Mrad}$; solvent, methanol. The conversion, including formation of homopolymer, was in all cases less than $10 \%(\mathrm{w} / \mathrm{w})$; the contact angle of the nongrafted polyethylene films was $89^{\circ} \pm 2$. 


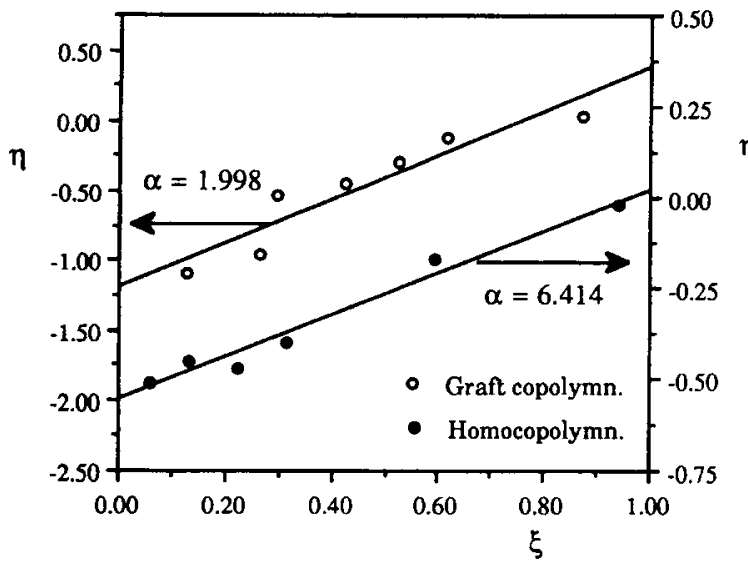

Figure 5 Plots of $\eta$ vs. $\xi$ for the monomer reactivity ratios determination by the Kelen-Tudos method.

essary to study the homogeneous copolymerization of VCA and VIMA using the same solvent and the same total monomer concentration as in the graft copolymerization. Therefore, copolymerizations of VCA and VIMA in methanol have been investigated at $50^{\circ} \mathrm{C}$, using AIBN as initiator with a total monomer concentration of $2.0 \mathrm{~mol} / \mathrm{L}$ (Table IV). The monomer reactivity ratios were calculated as $r_{1(\mathrm{VCA})}$ $=0.024 \pm 0.001$ and $r_{2 \text { (VIMA) }}=3.59 \pm 0.11$, respectively, on the basis of a plot of $\eta$ vs. $\xi$ according to the Kelen-Tudos eq. (3), ${ }^{40}$ using the results from Table IV (Fig. 5). Comparison of the $r_{1}$ and $r_{2}$ values for the homogeneous copolymerization of VCA and VIMA in methanol with those in acetone shows that there is only a moderate effect of the solvent on the monomer reactivity ratios.

Figure 6 illustrates that for a given mol fraction of VCA in solutions of the monomers, the VCA content in the graft copolymers was always found to be higher than in the copolymers obtained by homogeneous copolymerization. Comparison of the monomer reactivity ratios in the graft copolymerization, with those in the homogeneous copolymerization of VCA and VIMA, suggests that in the graft copolymerization, VCA shows a higher reactivity than in the homogeneous copolymerization, whereas VIMA exhibits the contrary.

Referring to the results that have been shown, it was found that (a) an increase of the VCA content in the solution reduces the total grafting yield, (b) grafting of VCA from binary solutions is promoted by the presence of VIMA, and (c) the VCA content in the graft copolymers is always higher than in the copolymers obtained by homogeneous copolymerization using the same VCA mol fraction in the feed. To explain these results, the monomer reactivity
Table IV Homogeneous Copolymerization of VCA (1) with VIMA (2) in Methanol at $50^{\circ} \mathrm{C}^{\mathrm{a}, \mathrm{b}, \mathrm{c}}$

\begin{tabular}{|c|c|c|c|c|}
\hline No. & $f_{\mathrm{vCA}}$ & $\begin{array}{l}\text { Polymn. Time } \\
(\mathrm{min})\end{array}$ & $\begin{array}{l}\text { Yield } \\
(\% \mathrm{w} / \mathrm{w})\end{array}$ & $\mathrm{F}_{\mathrm{VCA}}$ \\
\hline 1 & 0.10 & 75 & 1.0 & 0.03 \\
\hline 2 & 0.20 & 80 & 2.0 & 0.06 \\
\hline 3 & 0.30 & 90 & 2.0 & 0.09 \\
\hline 4 & 0.40 & 100 & 3.2 & 0.13 \\
\hline 5 & 0.50 & 110 & 1.8 & 0.14 \\
\hline 6 & 0.60 & 120 & 2.2 & 0.17 \\
\hline 7 & 0.80 & 140 & 0.8 & 0.30 \\
\hline 8 & 0.90 & 160 & 0.5 & 0.44 \\
\hline
\end{tabular}

Total monomer concentration $[\mathrm{VCA}]+[\mathrm{VIMA}]=2.0$ $\mathrm{mol} / \mathrm{L}$.

${ }^{\mathrm{b}}$ Initiator concentration [AIBN] $=6 \times 10^{-3} \mathrm{~mol} / \mathrm{L}$.

c VCA content in the copolymers was determined by FT-IR using a calibration curve of the corresponding VCA-VIMA copolymers with known composition. ${ }^{23}$

ratios ${ }^{35,36}$ and the partitioning of the monomers between the solvent and the polymeric substrate have to be taken into account. ${ }^{11,41}$

In the graft copolymerization with mixtures of VCA and VIMA onto the polyethylene films, the following reactions may be envisaged ${ }^{35}$ :

$$
\begin{gathered}
\mathrm{PE}^{*}+\mathrm{VCA}^{\stackrel{k_{i, 1}}{\rightarrow}} \mathrm{PE}-\mathrm{VCA}^{\bullet} \\
\mathrm{PE}^{\bullet}+\mathrm{VIMA}^{k_{i, 2}} \rightarrow \mathrm{PE}^{-} \mathrm{VIMA}^{\bullet}
\end{gathered}
$$

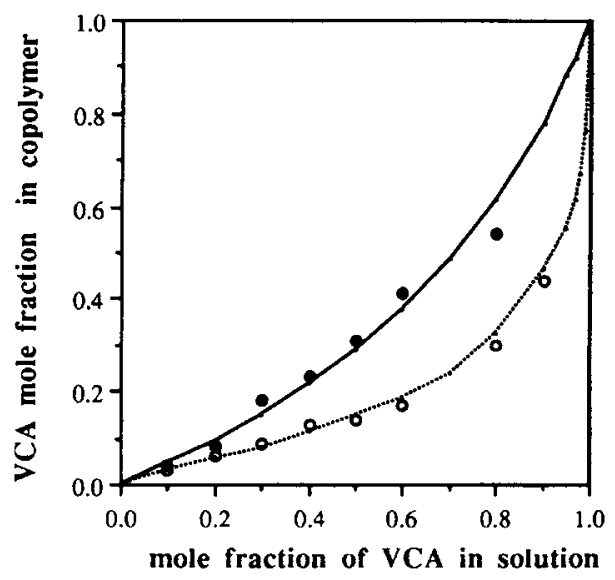

Figure 6 Effect of VCA content in solutions on the VCA content in VCA-VIMA copolymers: $(O)$ homogeneous copolymerization in methanol at $50^{\circ} \mathrm{C}$ using AIBN as initiator with [VCA] + [VIMA] $=2.0 \mathrm{~mol} / \mathrm{L}$ and [AIBN] $=6 \times 10^{-3} \mathrm{~mol} / \mathrm{L} ;(\bullet)$ graft copolymerization in methanol by $\gamma$-irradiation at ambient temperature with [VCA] $+[$ VIMA] $=2.0 \mathrm{~mol} / \mathrm{L}$ and radiation dose, $2.5 \mathrm{Mrad}$; dose rate, $0.4 \mathrm{Mrad} / \mathrm{h} ;(\cdots \cdots)$ based on $r_{1}=0.024, r_{2}$ $=3.59$; (-) based on $r_{1}=0.38, r_{2}=2.39$. 


$$
\begin{aligned}
& \mathrm{PE}-\mathrm{VCA}^{\bullet}+\mathrm{VCA} \stackrel{k_{11}}{\rightarrow} \text { PE-VCA-VCA }{ }^{\cdot} \\
& \text { PE-VCA }{ }^{\bullet}+\mathrm{VIMA}^{\stackrel{k_{12}}{\rightarrow} \text { PE-VCA-VIMA }} \\
& \text { PE-VIMA }+ \text { VCA } \stackrel{k_{21}}{\rightarrow} \text { PE-VIMA-VCA } \\
& \text { PE-VIMA }{ }^{*}+{\text { VIMA } \stackrel{k_{22}}{\rightarrow} \text { PE-VIMA-VIMA }}^{*}
\end{aligned}
$$

Reactions (4) and (5) indicate the initiation of the graft polymerization on the polyethylene film, which is determined by the relative molecular reactivities ${ }^{35,36}$ of the monomers toward the macroradicals generated on the PE films by $\gamma$-irradiation. The reactions $(6)-(9)$ are referred to the propagation reactions to form graft copolymers on the polymeric substrate. From our study of the homogeneous copolymerization of VCA and VIMA, it was found that $r_{1}=k_{11} / k_{12}=0.024$ and $r_{2}=k_{22} / k_{21}$ $=3.59$. Therefore, $k_{12} \gg k_{11}$ and $k_{22}>k_{21}$, which means that both types of growing radicals prefer to react with the same monomer (VIMA). Because of the preference of the growing radicals to react with VIMA, it can be envisaged that a decrease of the VIMA content in the monomer mixtures will influence the grafting yield. With increasing VCA content in the mixed monomer solutions, the total grafting yield will diminish because the contribution of the reactions (5), (7), and (9) decreases. At the same time, the contribution of the reactions (4), (6), and (8) will increase, however, grafting will occur to a much lower extent, as shown in Figure 4.

The effect of increased grafting of VCA in the presence of VIMA, that is, a positive synergism, as shown in Figure 4, might indicate that $k_{21}>k_{11}$ (reactions (8) and (6), respectively). However, although from the homogeneous copolymerization $r_{2}$ has been determined, no conclusions can be drawn because the $k_{11}$ and $k_{22}$ values are not known.

Grafting yields, as well as the VCA content in the graft copolymers, depended on the monomer ratios and the total monomer concentrations (Fig. 3). With a constant monomer ratio, the VCA content in the graft copolymers increased with the total monomer concentration to a certain value and then levelled off or decreased slightly. It is worth noting that a similar relationship of the VCA content in the graft copolymers with the total monomer concentration was observed in the graft copolymerization of VCA with N-vinylpyrrolidone (NVP) on polyethylene films. ${ }^{42} \mathrm{~A}$ dependence of the copolymer composition on the total monomer concentration in the feed was also found in other homogeneous copolymerizations. ${ }^{43}$

From the analysis of the VCA-VIMA grafts on the polyethylene films, a higher $r_{1}$ value was found $\left(r_{1}=0.38\right)$ than in the homogeneous copolymerizations $\left(r_{1}=0.024\right)$. In order to understand this result, Harwood's concept of the "bootstrap effect" might be helpful. ${ }^{44} \mathrm{He}$ analyzed solvent effects in copolymerizations involving polar monomers and concluded that partitioning of monomers between solvent and the growing polymer radical is a very significant phenomenon. Although in Harwood's article only the effect of solvents on homogeneous copolymerizations was discussed, his model could possibly be used for the interpretation of the results of our graft copolymerizations.

In the model of Harwood, it was argued that the concentration of monomers and the ratios of the monomer concentrations, which govern the addition of the particular monomer on the growing chains, may not be the same throughout. These parameters may be different in the vicinity of a growing chain as compared with the composition charged to the polymerization system. Based on this model, the conditional probability that an $\mathbf{M}_{1}$ unit follows an $\mathbf{M}_{2}$ unit in a growing chain $\mathbf{P}\left(\mathrm{M}_{1} / \mathrm{M}_{2}\right)$ can be represented as ${ }^{44}$ :

$$
\text { or } \begin{aligned}
& \mathbf{P}\left(\mathbf{M}_{1} / \mathbf{M}_{2}\right)=1 /\left(1+r_{2}\left[\mathbf{M}_{2}\right] /\left[\mathbf{M}_{1}\right]\right) \\
& \mathbf{P}\left(\mathbf{M}_{1} / \mathbf{M}_{2}\right)=1 /\left(1+r_{2} k\left[\mathbf{M}_{2}^{0}\right] /\left[\mathbf{M}_{1}^{0}\right]\right)
\end{aligned}
$$

where $\left[\mathrm{M}_{1}\right],\left[\mathrm{M}_{2}\right]$, and $\left[\mathrm{M}_{1}^{0}\right],\left[\mathrm{M}_{2}^{0}\right]$ are the monomer concentration in the vicinity of the growing radical and the monomer concentration charged to the polymerization system, respectively; $r_{2}$ is the monomer reactivity ratio for $\mathbf{M}_{2} ; k=\left[\mathbf{M}_{1}^{0}\right]\left[\mathbf{M}_{2}\right] /$ $\left[\mathbf{M}_{2}^{0}\right]\left[\mathbf{M}_{1}\right]$ is the partition coefficient.

In our case, since a known apolar substrate, that is, polyethylene, was used, and since VCA is more hydrophobic than VIMA, the relatively hydrophobic VCA should be more compatible with the polymeric substrate than the more hydrophilic VIMA. Especially with a polar solvent (in this case methanol), the polyethylene films will be preferentially surrounded by VCA. Therefore, during the grafting reaction in the vicinity of the growing radical, that is, surrounding the apolar polyethylene film, the local VCA $\left(M_{1}\right)$ concentration may be higher, which means that the partition coefficient $k$ is smaller than one. The probability that a $\mathbf{M}_{1}$ monomer will add to a $\mathrm{M}_{2}$ unit in a growing graft chain is higher than in a homogeneous copolymerization, where $k$ is supposed to be one, while the probability of the addition of a $M_{2}$ monomer to a $M_{1}$ unit in a growing chain will be lower. This would mean that graft copolymers with a higher VCA content than in the copolymers 
Table V Comparison of VCA Content in VCA-VIMA Graft Copolymers and in VCA-VIMA Copolymers Obtained by Homogeneous Copolymerizations ${ }^{a}$

\begin{tabular}{ccccc}
\hline$f_{\mathrm{VCA}}$ & $\mathrm{F}_{\mathrm{VCA}}{ }^{\mathrm{b}}$ & $\mathrm{F}_{\mathrm{VCA}}{ }^{\mathrm{c}}$ & $\mathbf{F}_{\mathrm{VCA}}{ }^{\mathrm{d}}$ & $\mathbf{F}_{\mathrm{VCA}}{ }^{\mathrm{e}}$ \\
\hline 0.20 & 0.08 & 0.06 & 0.06 & - \\
0.40 & 0.23 & 0.09 & 0.13 & 0.10 \\
\hline
\end{tabular}
L.

a Solvent, methanol; total monomer concentration, $2.0 \mathrm{~mol} /$

${ }^{\mathrm{b}}$ VCA content in graft copolymers on polyethylene films.

c VCA content in copolymers isolated from the graft solutions (total conversion, less than $10 \%(\mathrm{w} / \mathrm{w})$ ).

${ }^{d}$ VCA content in copolymers obtained by homogeneous copolymerization using AIBN as initiator at $50^{\circ} \mathrm{C}$ (see also Table IV).

' VCA content in copolymers obtained by homogeneous copolymerization with $\gamma$-irradiation (2.5 Mrad, with a dose rate of $0.4 \mathrm{Mrad} / \mathrm{h}$, without LDPE film) at ambient temperature (conversion $6 \% \mathrm{w} / \mathrm{w}$ ).

obtained by homogeneous copolymerization would be obtained, which was actually observed (Fig. 6). In fact, copolymers from the graft solutions could also be isolated with VCA contents comparable to those obtained by homogeneous copolymerizations, but lower than in the graft copolymers (Table V).

Harwood et al. proved that copolymers having the same composition have the same microstructure, which suggests that the same monomer reactivity ratios were applicable for all solvent systems and that the role of the solvent was to influence the ratio of monomer concentrations available to the propagating radicals. ${ }^{44-47}$ In other words, based on the "bootstrap" model, the monomer reactivity ratios remain the same for certain monomer pairs in all copolymerization systems.

Although no information is available about the microstructure of the VCA-VIMA copolymers and the VCA-VIMA grafts, Harwood's concept seems useful to explain our results. Therefore, in our work, the different monomer reactivity ratios and the relatively higher VCA contents in the graft copolymers compared to that in the copolymers obtained by homogeneous copolymerization are probably not caused by a change of the monomer reactivities but by different partitioning of the two monomers between the solvent and the growing polymer radicals. As a result, the monomer ratios in the vicinity of the growing centers differ from those charged to the polymerization, and the monomer reactivity ratios obtained in the graft copolymerization will be the products of the true reactivity ratios and the partitioning coefficients ( see eq. 11).

Also, in other graft copolymerization systems, partitioning of monomers between the solvent and the polymeric substrate has been suggested. Cohn et al. ${ }^{11}$ investigated the graft copolymerization of 2 hydroxyethyl methacrylate (HEMA) and ethyl methacrylate (EMA) in an ethanol-water mixture (90.6 : 9.4) onto LDPE films by the mutual irradiation technique and explained the results assuming a more favorable partitioning of the relatively hydrophobic EMA into the apolar polyethylene substrate. More recently, Sankholkar and $\mathrm{Deb}^{41} \mathrm{re}-$ ported the graft copolymerization of mixtures of methyl methacrylate (MMA) and methacrylic acid (MAA) in cyclohexanone onto poly (vinyl chloride) and chlorinated rubber. They found a higher MMA content in the grafted copolymers than expected on the basis of values of $r_{1}$ and $r_{2}$ for the homogeneous copolymerization. According to these authors, a preferential solvation of the backbone polymer by MMA could be a possibility to explain qualitatively the observed anomalous grafted chain composition. Partitioning of monomers between solvent and polymeric substrate was also indicated in the graft copolymerization of VCA with $\mathrm{N}$-vinylpyrrolidone on polyethylene films. ${ }^{42}$

The "bootstrap" model clearly illustrates the important role of the solvent in copolymerizations. Increasing the polarity of a solvent may change the partitioning coefficient of the monomers surrounding the growing centers. It means that if a more polar solvent is used, the favorable partitioning of

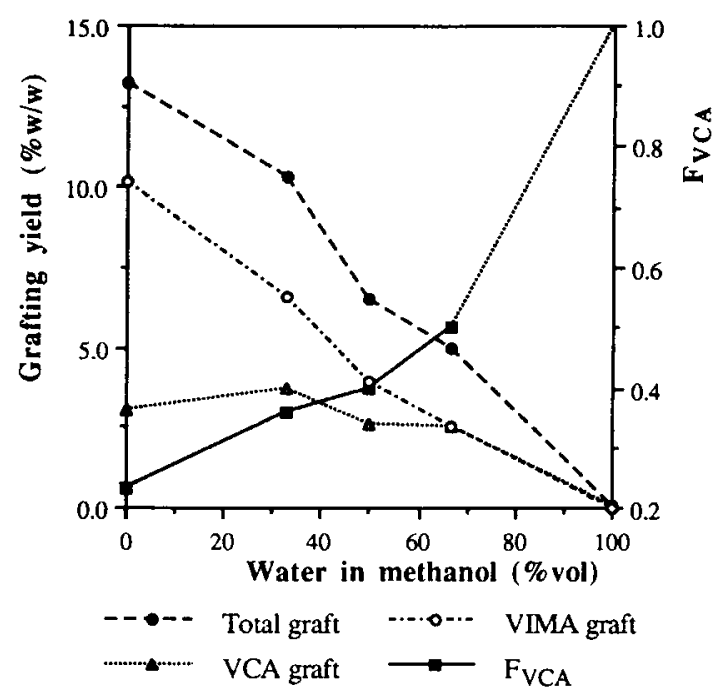

Figure 7 Effect of solvent composition on the grafting yields and the VCA content in VCA-VIMA graft copolymers. Grafting conditions: total monomer concentration, $2.0 \mathrm{~mol} / \mathrm{L}$; radiation dose, $2.5 \mathrm{Mrad}$; dose rate, $0.4 \mathrm{Mrad} /$ h; molar ratio of VCA to VIMA, 40/60. 
VCA into an apolar polymer (polyethylene) may become more efficient, and a relatively higher VCA content in the graft copolymer would be expected. In order to prove this hypothesis, mixtures of water and methanol have been investigated as solvents for the graft copolymerization of mixtures of VCA and VIMA onto LDPE films. Figure 7 shows the effect of the solvent composition on the grafting yield and on the VCA content in the graft copolymers and it is obvious that the VCA content in the graft copolymers is raised with increasing polarity of the solvent.

However, with the increase in the water content, the total grafting yield markedly decreased, with the grafting yield of VIMA following the same trend. The VCA grafting yield remained almost the same until a water content of about $70 \%$. In $100 \%$ water, the grafting yield was about $0.1 \%(\mathrm{w} / \mathrm{w})$ and on the polyethylene film only the presence of VCA groups could be detected. The decrease of the total grafting yield may be caused by the more favorable partitioning of VCA surrounding the PE films, which reduces the local concentration of the VIMA around the PE films, resulting in a decrease of reactions (5), (7), and (9). In $100 \%$ water, the very hydrophobic polyethylene film will be mainly surrounded by VCA, the amount of VIMA is small, thus, the grafting yield becomes low due to the low addition rate of VCA to the growing radical on the PE film, thus reducing the graft reaction. It should be noted that, in the grafting experiments in the methanolwater mixtures, the formation of copolymers from the graft solution increased from $6 \%$ (water content $0 \%$ ) to $20 \%$ (water content $100 \%$ ). Probably this competition between homogeneous copolymerization and graft copolymerization also resulted in a decrease of the total grafting yield.

From the above results, the conclusion can be drawn that an increase of the polarity of the solvent seems to affect the partitioning of the monomers into the polymeric substrate, leading to a higher content in the graft of the more compatible VCA.

\section{CONCLUSIONS}

It was shown in this study that grafting of VCA onto polyethylene films resulted in low grafting yields. Using VIMA as a comonomer, the amount of functionally reactive VCA groups could be increased substantially and also the hydrophilicity of the surface could be improved.

Monomer reactivity ratios of VCA and VIMA in the graft copolymerization differed from those in the homogeneous copolymerization. A preferential partitioning of the monomers between the solvent and the substrate in the graft copolymerization was assumed to explain this difference.

The authors are grateful to the Dutch Organization for Scientific Research (NWO) for providing financial support for the project and to Prof. Dr. A. L. German, Technical University of Eindhoven, The Netherlands, for helpful discussions.

\section{REFERENCES}

1. J. D. Andrade, H. B. Lee, M. S. John, S. W. Kim, and J. B. Nibbs, Jr., Trans. Am. Soc. Artif. Intern. Organs, 19, 1 (1973).

2. J. D. Andrade, Med. Instrum., 7, 110 (1973).

3. H. B. Lee, H. S. Shim, and J. D. Andrade, Polym. Prepr. Am. Chem. Soc., 13, 729 (1972).

4. B. D. Ratner and A. S. Hoffman, J. Appl. Polym. Sci., 18, 3183 (1974).

5. B. D. Ratner and A. S. Hoffman, Am. Chem. Soc. Symp. Ser., 31, 1 (1976).

6. X. D. Feng, Polymer J., 17, 189 (1985).

7. D. Kaelble and J. Moacanin, Proc. of 1st Cleveland Symp. Macrostructure and Properties of Biopolymers, Cleveland, Ohio, October, 1976.

8. B. D. Ratner, A. S. Hoffman, S. R. Hanson, L. A. Hark, and J. D. Whiffen, J. Polym. Sci. Polym. Symp., 66, 363 (1979).

9. A. S. Hoffman, Radiation Phys. Chem., 18, 323 (1981).

10. T. Sasaki, B. D. Ratner, and A. S. Hoffman, Am. Chem. Soc. Symp. Ser., 31, 283 (1976).

11. D. Cohn, A. S. Hoffman, and B. D. Ratner, J. Appl. Polym. Sci., 29, 2645 (1984).

12. J. E. Wilson, Polym. Plast. Technol. Eng., 16, 119 (1981).

13. C. D. Ebert, E. S. Lee, and S. W. Kim, J. Biomed. Mater. Res., 16, 629 (1982).

14. Y. Imanishi, Y. Ito, L. S. Liu, and M. Kajihara, $J$. Macromol. Sci. Chem., A25, 555 (1988).

15. K. Allmer, J. Hilborn, P. H. Larsson, A. Hult, and B. Rånby, J. Polym. Sci. Part A Polym. Chem., 28, 173 (1990).

16. G. H. Hsiue, C. C. Wang, C. Y. Chen, and C. J. Chang, Ang. Makromol. Chem., 179, 149 (1990).

17. D. Muller-Schulte and F. A. Horster, Polym. Bull., 7, 77 (1982).

18. H. Huemer and R. Schmidtberger, Ger. Offen $2,552,510$ (1977).

19. O. Mauz and K. Sauber, Ann. N.Y. Acad. Sci., 434, 251 (1984).

20. O. Mauz, K. Sauber, and S. Noetzel, Ger. Offen DE 3,243,591 (1982).

21. J. P. Fischer, U. Becker, S. P. von Halasz, K. F. Muck, H. B. Puschner, S. Rosinger, A. Schmidt, and H. H. Suhr, J. Polym. Sci. Polym. Symp., 66, 443 (1979). 
22. G. Kovacs, N. Fedorova, L. Kiss, and T. Killy, IUPAC Macromol. Symp., 28, 396 (1982).

23. G. H. Chen, L. van der Does, and A. Bantjes, J. Appl. Polym. Sci. Symp. Ed., 48, 545 (1991).

24. B. Jansen and G. Ellinghorst, J. Polym. Sci. Polym. Symp., 66, 465 (1979).

25. J. X. Huang, G. H. Chen, E. J. Tijsma, L. van der Does, and A. Bantjes, Chin. J. Polym. Sci., 8, 197 (1990).

26. E. J. Tijsma, G. H. Chen, L. van der Does, and A. Bantjes, Makromol. Chem. Rapid Commun., 11, 501 (1990).

27. R. N. King, J. D. Andrade, and S. M. Ma, J. Coll. Interf. Sci, 103, 62 (1985).

28. B. Jansen, H. Steinhauser, and W. Prohaska, Makromol. Chem. Makromol. Symp., 5, 237 (1986).

29. K. D. N. Lawrence and D. Verdin, J. Appl. Polym. Sci., 17, 2658 (1973).

30. M. Anbar and P. Neta, Int. J. Appl. Radiat. Isot., 18, 493 (1967).

31. S. N. Bhattacharyya and D. Maldas, J. Polym. Sci. Polym. Chem. Ed., 20, 939 (1982).

32. E. A. Hegazy, N. H. Taher, A. R. Ebaid, A. G. Rabie, and H. Kamal, J. Appl. Polym. Sci., 39, 1029 (1990).

33. A. Hebeish, S. Shalaby, and A. Bayazeed, J. Appl. Polym. Sci., 27, 197 (1982).

34. H. T. Lokhaude, M. D. Teli, K. N. Rao, and M. H. Rao, J. Appl. Polym. Sci., 29, 1843 (1984).
35. J. A. Harris and J. C. Arthur, Jr., J. Appl. Polym. Sci., 14, 3113 (1970).

36. S. N. Bhattacharyya, D. Maldas, and V. K. Pandey, J. Polym. Sci. Part A Polym. Chem., 24, 2507 (1986).

37. G. Odian, A. Rooi, E. Ratchik, and T. Acker, J. Polym. Sci., 54, 159 (1961).

38. G. Odian, T. Acker, A. Rossi, and E. Ratchik, J. Polym. Sci., 57, 661 (1962).

39. G. Odian, R. L. Kruse, and J. H. T. Kho, J. Polym. Sci. Part A1, 9, 91 (1971).

40. T. Kelen and F. Tudos, J. Macromol. Sci. Chem., A9, 1 (1975).

41. S. Sankholkar and P. C. Deb, J. Appl. Polym. Sci., 39, 1681 (1990).

42. G. H. Chen et al., in preparation.

43. A. L. German et al., Private communication.

44. H. J. Harwood, Makromol. Chem. Macromol. Symp., 10/11, 331 (1987).

45. K. Plochocka and H. J. Harwood, Am. Chem. Soc. Div. Polym. Chem. Polym. Prepr., 19, 240 (1978).

46. K. Y. Park, E. R. Santee, and H. J. Harwood, Eur. Polym. J., 25, 651 (1989).

47. T. P. Davis, Polymer Commun., 31, 442 (1990).

Received June 6, 1991

Accepted August 21, 1991 